\title{
Linguistics as Metaphor in Organizational Regularization and Decay
}

\author{
Marc S. Mentzer \\ University of Saskatchewan
}

Linguists have found that the twin tendencies of regularization and decay lead to the development of language structures that are simultaneously complex and unstable. This serves as a metaphor to illuminate the parallel processes of regularization and decay in organizational structure. Both the evolution of languages and the evolution of organizational structures reflect the desire to minimize cognitive work, as shown in the embracing of cognitive order while simultaneously seeking the course of least resistance.

Keywords: formalization, life cycle, linguistics, punctuated equilibrium, regularization

\section{INTRODUCTION}

Every time a professor grades a stack of student papers, there is more evidence that the English language is decaying. The rules of English usage are blatantly ignored. There is sloppiness in grammar, sloppiness in spelling, and sloppiness in syntax. This tendency to violate established structures is present in many forms of human behavior, and here it will be argued that patterns of change in language serve as a useful metaphor in understanding parallel processes as organizations evolve.

For the hypothetical professor grumbling over students' sloppiness in writing, it is important to note that this is not a new complaint, and in fact, one could argue that spellcheckers and grammar checkers have improved the standard of English usage or at least braked its deterioration. There have been complaints about the downward trend in English usage as far back as Jonathan Swift in 1712, and similar complaints arise in other languages (Crystal, 2004). Prior to the 1700s, people did not complain about English usage, simply because there was no consensus about what the rules should be, especially regarding written usage, comprising a situation far more chaotic than the current state of English. Despite nostalgia for when everyone (supposedly) used English correctly, there has never been a golden age of correct English usage. In the history of the English language, as soon as widely accepted rules arose, complaints arose that people were careless in following them.

Today's incorrect usage sometimes evolves into tomorrow's correct usage. Deutscher's (2005) The Unfolding of Language explains how this steady decay is counterbalanced by new forms of linguistic rigidity or regularization that spontaneously arise. Can an examination of these opposing forces in language, decay and regularization, serve as a metaphor to help us understand how organizations evolve?

\section{REGULARIZATION}

Consider these passages which might be said by a toddler in an English-speaking family: 
"He goed to the store"

"There are two mouses in the cage."

It is obvious that the child, who hasn't yet learned which usages are irregular, is applying regular language structures indiscriminately. From a different perspective, these toddler phrases can be regarded as efforts to regularize the language, in other words, to impose a rigid structure on English usage where there had not been such a rigid structure before. The toddler does this because it is instinctive that things ought to form a pattern. Also, the toddler does this because it is easier than learning all the irregular forms, even though the toddler will eventually be forced to learn those anyway. Forcing irregular usages into a systematic, rational language structure is actually a labor-saving device and an expression of the intrinsic human tendency to minimize cognitive load. In short, the human mind craves order because order is easier and more comfortable.

The quest for cognitive order is not a phenomenon limited to language usage. A person's search for cognitive order has also been identified as a driving force in organizational restructuring, as executives reconfigure their organization to quiet any sense of uneasiness about mismatch between structure and environment (McKinley \& Scherer, 2000). In this context, cognitive order is related to Weick's (1969) concept of equivocality removal, in which managers embrace rules to aid in choosing among conflicting interpretations.

It does not require an enormous leap of the imagination to consider that the cute toddler phrases above might become standard English a century from now. Why not say "he goed" instead of "he went"? Linguists are quick to point out that the legitimation of such changes arises from adult short cuts, not juvenile usages (Aitchison, 2001), but nonetheless these examples illustrate how linguistic structures can become more formalized and more regular over time. Such conversions of irregular plural nouns into regular plural nouns have already been occurring for centuries. Until the fourteenth century, the plural of "eye" was "eyn." Likewise, the plural of "cow" was "kine," the plural of "book" was "bec," and the plural of "hand" was "hend" (Deutscher, 2005). Those irregular plurals are obsolete, and now one says "eyes," "cows," and so on, illustrating a trajectory toward increased regularization.

This process of regularization is continuing at the very moment. Consider how "persons," in contrast to "people," is now an accepted plural form, whereas forty years ago any schoolteacher would have marked it as incorrect, no doubt while complaining to colleagues about the declining standard of English usage. In an increasing number of contexts, the word "people" just doesn't sound right, and it is only a matter of time until "persons" becomes the only accepted plural form of "person." As well, note that the Toronto hockey team is the "Maple Leafs," not the "Maple Leaves." Will "leafs" eventually become the accepted usage? If so, it would be part of a long pattern of irregular plural forms becoming regularized, as "leaves" joins "eyn" on the list of archaic words.

The same process of regularization is occurring to verbs. Consider an irregular verb that is becoming regularized in our own time: Aitchison (2001) points out that "shooted" has become standard usage in the context of drug abuse (e.g., "He shooted up with a new needle" - one would not say "He shot up with a new needle.") All of these examples, whether nouns or verbs, echo the natural search for structure as a way of minimizing cognitive work. Thinking and talking are slightly easier if a person doesn't have to remember irregular plurals like "eyn," "kine," or "people."

The logical conclusion is that eventually all irregular noun and verb forms will be dropped from the English language. ("The two mouses goed under the couch.") Ultimately English will become a perfectly regular language, or so a person might hypothesize. If this argument was valid, English would have become a perfectly regular language centuries ago. Evidently there is an opposing trend of decay that works against the trend toward regularity.

\section{DECAY}

If the long-term trend is that irregular forms are dropped, how did those irregular noun and verb forms come into existence in the first place? Irregular usages develop as shortcuts because they take less effort. 
This is the underlying paradox of language evolution: The endless search for shortcuts causes the twin opposing phenomena of increased regularity and increased irregularity. Later, it will be argued that these countervailing processes of linguistic evolution are mirrored in the evolution of organizations.

This paradox, in which minimization of the cognitive workload causes simultaneous rigidity and deterioration in language, is rooted in innate cognitive tendencies. Similar phenomena should be expected in other outcomes of cognitive functioning, as in the way in which organizations change over time. The evolution of a given organization reflects both the search for structures in which to regularize organizational activity, as well as the search for shortcuts.

The search for ways to regularize organizational activity is exemplified in organizations' tendency toward greater formalization. As people grapple with language, just as they grapple with functioning within an organization, there is always the search for a structure that can be applied to the situation so as to reduce one's cognitive load, or what might be termed the search for economy in cognitive processes. Rather than pausing a microsecond before each verb to recall whether it is regular or irregular, a person such as the toddler above finds it tempting to force every verb into a regular structure (e.g., "He goed to the store."). In organizational functioning, it is a burden to consider each situation on a case-by-case basis, and much easier to create a structure of decision rules that can be applied universally, or in other words, a procedure manual. The creation of mechanistic organizational structures and the creation of rigid language structures are both the result of innate cognitive tendencies to reduce cognitive load. Once again, the craving of the human mind for order is evident.

In English, there are many examples of irregular forms being transformed into regular forms (e.g., "persons"), and similarly there are many examples of rigid linguistic structures decaying as irregular forms are created.

For example, what is the past tense of "to sneak"? As Finegan (2003) explains, the correct past tense is "sneaked," but "snuck" is gradually replacing "sneaked." Finegan points out that in recent US legal documents, "snuck" is used one-third of the time and is increasing in popularity, while "sneaked" is used two-thirds of the time. "Snuck" was once viewed as nonstandard, in the same category as "ain't," but is increasing in legitimacy, an example of an irregular verb being created before our eyes.

As another example, what is the past tense of "to dive"? Traditionally, the correct answer is "dived," but "dove" ("She dove into the pool") is increasingly common, and provides another instance of an irregular verb being created in our own time. The verb form "dove" began as a nonstandard usage in the northeastern US and has since spread nationwide. Deutscher (2005) describes how the human mind, in its search for regularity and patterns, construes "dive/dove" as analogous to the established usage, "drive/drove." Hence this transition simultaneously illustrates the breakdown of an existing linguistic rule (past tenses use "-ed") and the creation of a new rule (verbs ending in "-ive" are changed to "ove" to make the past tense). The creation of "dive/dove" illustrates how regularization and decay occur at the same time.

Today we might hear someone say, "She snuck into the pool and dove into the deep end," a sentence that would have been regarded as incorrect a few decades ago, exemplifying the paradox that the English language is simultaneously decaying and becoming regularized.

The above discussion is limited to English, but similar processes occur in all languages; there is no such thing as a static, unchanging language. Although the pace and nature of change will vary among languages, all are subject to the dual opposing forces of regularization and decay. This discussion has focussed on a few aspects of language, namely irregular nouns and verbs, but similar phenomena cause changes in syntax, spelling, pronunciation, and other aspects of language (Labov, 1994).

\section{LINGUISTICS AS METAPHOR}

Organizational scholars have often looked to the biological sciences for inspiration in advancing organization theory, and likewise the discipline of linguistics provides a metaphor for re-examining organizational phenomena (Cornelissen, 2005).

People seek to minimize their cognitive load, in part as a way of reducing stress. Cognitive load can be minimized either by using a comfortable structure or by taking shortcuts. For example, in driving, the desire 
to make things easier for oneself will take the form of following traffic rules, while on other occasions the desire to make things easier will take the form of violating traffic rules, such as rolling through stop signs. This desire to minimize cognitive load is evident in nearly every type of human behavior, taking the forms of embracing cognitive order as well as taking the course of least resistance. Linguists have found that these twin tendencies lead to the development of language structures that are simultaneously complex and unstable. Aitchison (2001) has described the evolution of languages as "a continuous pull between the disruption and restoration of patterns.... Disruptive and therapeutic tendencies vie with one another, with neither one totally winning or losing, resulting in a perpetual stalemate [p. 253]." In a similar manner, as organizations age, structures evolve that are complex yet unstable, as when a procedure manual is followed on some occasions and violated on others.

Organizational scholars have long recognized the tendency of organizations to become more highly structured (i.e., more formalized and mechanistic) over the passage of time. These conceptual models sometimes take the form of a life cycle, of which Greiner's (1972) and Quinn and Cameron's (1983) might be the best known. However, limited attention has been given to the contrary pressures to "cut corners" amidst increasing formalization. Even when a life cycle model takes into account a coordination or elaboration stage following maturation (Greiner, 1972; Quinn \& Cameron, 1983), it is assumed that coordinating mechanisms are imposed from above. An examination of the tension between regularization and decay in language can lead scholars to search for spontaneous, informal processes in organizations that mitigate the impact of excessive rigidity.

Consider this hypothetical example: Because office supplies are mysteriously disappearing at a fast rate, a company institutes a procedure whereby all supplies are kept in a supply room overseen by an employee, who has been instructed to give office supplies only when presented with a newly-designed supply requisition form that has been duly filled out by the requesting employee. This procedure continues for a while amidst grumbling by employees that they have to fill out a form every time they want a box of paperclips. Eventually, one employee becomes fed up, walks into the supply room, and simply grabs a box of paperclips amidst futile objections by the employee overseeing the room. Others hear of this, and other employees brusquely defy the employee and take what they want without adhering to the necessary procedures.

At this point several outcomes are possible: The disobedient employee might be reprimanded by a higher authority and revert back to following the rules, and management might even apply harsher controls to discourage future disobedience. A second possibility is that the status quo continues in which some employees follow procedures and others do not. Yet another possible outcome is that this outburst of disobedience spreads to other office processes as the legitimacy of the company's formal procedures becomes undermined. There is, of course, no reason to expect that the opposing forces of regularization and decay will be in a state of equilibrium, and it is certainly possible that the outcome will be either excessive rigidity or excessive informality that threatens the viability of the organization.

While the increase in organizational formalization or mechanistic tendencies over time has been well documented, less attention has been given to counter-mechanistic behaviors as organization members "do an end run" around rules and procedures. In extreme cases, an organization rule might be so widely flouted that it is only the least powerful or most naive members of an organization who follow the formal procedures. A closer examination of such rebellions against formal procedures could improve our understanding of what really happens in organizations as they evolve. These countervailing forces are parallel to the opposing tendencies in linguistic evolution in which rigid structures are created and violated at the same time. This is one approach through which an understanding of linguistic change can shed light on organizational phenomena.

\section{THE NON-LINEARITY OF CHANGE}

When the trend toward increasing formalization within organizations has been studied, the pace at which that change percolates through an organization has not always received full attention. It is simplistic to assume that the rate of change within an organization is a linear phenomenon (Amis, Slack, \& Hinings, 
2004). Linguists have established that when change occurs within a language, the pace of change follows a predictable S-curve (Aitchison, 1996; Chen, 1972). At first, a few speakers of a language slowly embrace the new language form, followed by a period in which the new language form is quickly adopted by the vast majority of speakers. Then, there is a period in which the remaining holdouts accept the new language form at a slow pace. Change in organizations is likely to follow a similar S-curve phenomenon of a few early adopters, then rapid acceptance among the majority of members, and lastly a few reticent individuals who are late adopters.

Similarly, language change is characterized by the punctuated equilibrium model, meaning periods of stasis or equilibrium that are punctuated by periods of major change (Dixon, 1997). This bears an uncanny similarity to Greiner's (1972) organizational life cycle, in which stages of change are separated by periods of crisis. An example would be when an entrepreneurial CEO of a growing organization realizes that micromanaging every employee is no longer effective, resulting in a major shift in the CEO's approach to control. This constitutes a crisis point in the evolution of the organization, as continued growth requires a new management approach in which the CEO's power is devolved to middle managers who gain substantial decision-making authority. In Greiner's model, growth continues until excessive "red tape" creates an additional crisis necessitating major changes in how the organization is structured. There are striking parallels to how languages alternate between periods of stasis and periods of substantial change.

\section{CONCLUSION}

While the concept of the life cycle has been a useful approach to studying organizations, there is no evidence for a comparable life cycle within a language. Languages die for many reasons, but never because the structure of the language has become excessively rigid or complex. For example, Latin is often regarded as a rigidly complex language, but Latin died because the associated political entity died, not vice versa, and in event, it can be argued that Latin still survives having gradually evolved into the Italian language. English, Russian, German and Japanese are thriving despite being highly complex, although characterizations of this type are unavoidably subjective and culturally biased; it is noteworthy that there is actually an inverse correlation between language complexity and technological development (Deutscher, 2005). On the other hand, an organization with an excessively complex internal structure will either die, especially if it is the private sector, or at a minimum, lose all effectiveness. To avoid oblivion, every organization must constantly walk a tightrope between anarchy and excessively complex structures, whilst there is no parallel threat to the viability of a language.

The study of how languages change reveals innate human predispositions to create structure while seeking shortcuts that violate that structure. Linguistic change, as a metaphor for change in organizations, elucidates the ongoing tension between regularization and decay, a dialectic present in many facets of human cognition.

\section{REFERENCES}

Aitchison, J. (1996). The seeds of speech: Language origin and evolution. Cambridge, UK: Cambridge University Press.

Aitchison, J. (2001). Language change: Progress or decay? (3rd ed.). Cambridge, UK: Cambridge University Press.

Amis, J., Slack, T., \& Hinings, C.R. (2004). The pace, sequence, and linearity of radical change. Academy of Management Journal, 47, 15-39.

Chen, M. (1972). The time dimension: Contribution toward a theory of sound change. Foundations of Language, 8, 457-498.

Cornelissen, J.P. (2005). Beyond compare: Metaphor in organization theory. Academy of Management Review, 30, 751-764.

Crystal, D. (2004). The stories of English. Woodstock, NY: Overlook Press. 
Deutscher, G. (2005). The unfolding of language: An evolutionary tour of mankind's greatest invention. New York: Henry Holt and Company.

Dixon, R.M.W. (1997). The rise and fall of languages. Cambridge, UK: Cambridge University Press.

Finegan, E. (2003). Linguistic prescription: Familiar practices and new perspectives. In M. McGroarty (Ed.), Annual Review of Applied Linguistics (23, 213-224). Cambridge, UK: Cambridge University Press.

Greiner, L. (1972, July-August). Evolution and revolution as organizations grow. Harvard Business Review, 50, 37-46.

Labov, W. (1994). Principles of linguistic change. Oxford, UK: Blackwell.

McKinley, W., \& Scherer, A.G. (2000). Some unanticipated consequences of organizational restructuring. Academy of Management Review, 25, 735-752.

Quinn, R.E., \& Cameron, K. (1983). Organizational life cycles and shifting criteria of effectiveness: Some preliminary evidence. Management Science, 29, 33-51.

Weick, K.E. (1969). The social psychology of organizing. Reading, MA: Addison-Wesley. 